\title{
A Review of Edible Packaging for Foods
}

\author{
Pooja Saklani ${ }^{1}$, Siddhnath ${ }^{1}$, Sambit Kishor Das ${ }^{2}$ and Shiv Mohan Singh ${ }^{3 *}$ \\ ${ }^{1}$ Department of Fish Processing Technology, Faculty of Fishery Sciences, \\ WBUAFS Kolkata, India \\ ${ }^{2}$ Department of Fish Processing Technology, Central Institute of Fisheries Education, \\ Mumbai, India \\ ${ }^{3}$ College of fishery science, NDVSU, Jabalpur, India \\ *Corresponding author
}

\section{A B S T R A C T}

Edible coatings or films have received considerable attention in recent years. Materials used in edible packaging (polysaccharide, lipid and protein-based and their

\section{Keywords}

Edible films, Environmental pollution,

Nutritional value, Industrial application, food products

Article Info

Accepted:

26 June 2019

Available Online:

10 July 2019 composites) have apparent advantages over synthetic films. It could contribute to the reduction of environmental pollution. The main advantage of edible films over synthetics is that these may be safely eaten as a part of the food products and are environment-friendly at the same time as they increase the shelf life of fresh products. By functioning as barriers, edible films feasibly reduce the complexity and thus improve the recyclability of packaging materials, compared to the more traditional non-environmental friendly packaging materials, and possess the potential to substitute synthetic polymer films. Plasticisers are generally added to edible films for enhancement in flexibility and durability. Antioxidants are added to edible packaging materials to delay the rate of oxidation reactions. One of the significant emerging functions of edible coatings is their use as carriers of antifungal and antimicrobials agents to enhance the shelf life of foods products; they also used as carriers of nutrients to increase the nutritional value of final processed food products. Potential applications of edible films as smart packaging needs research, which is still in its infancy and extension on its industrial use will be a breakthrough in the packaging industry.

\section{Introduction}

One-third of the produced food leads to waste yearly especially during transportation and storage due to physicochemical, microbial spoilage, oxidation, moisture changes and other factors (FAO, 2011; Hannon et al., 2017). The Decaying of food causes not only loss but also deterioration in nutritional and sensorial quality, which leads to illnesses or may even lead to toxicity (Gómez et al., 2014; Hadian et al., 2017). Advantage of Packaging of food processing after the process is complete, enabling foods to transport safely for long distances from their origin point and still be nutritious at the time of consumption 
(Ahmad et al., 2017; MacGowan and Macnaughton, 2017; Nordstrom and Malmsten, 2017; Ribeiro et al., 2017; Lin et al., 2018). A crucial function of food packaging is traceability, convenience, and tamper indication. It helps to make food is cost-effective in such a way that satisfies industry requirements and consumer desires, maintains food quality, safety, and reduces environmental impact (Marsh and Bugusu, 2007)

However, food packaging technology maintains food quality with other issues, including material costs and energy; enhance environmental and social consciousness and strict regulations on pollutants and disposal of municipal solid waste. Edible films and coatings are one of the emerging approaches for food-quality optimisation. Edible coatings and films have received considerable attention because of their advantages compared to synthetic films. One of the key benefits of using edible packaging systems, as compared to synthetic packaging systems, is that they are an integral part of the food product; they can be eaten, without unpack and throw the package (Bourtoom, 2008; Ali et al., 2010; Trinetta, 2016). The increased interest in edible coatings has been motivated by increasing consumer demand for safe, convenient, and stable foods, and the awareness of the adverse environmental effects of non-biodegradable packaging (Bourtoom, 2008; Donhowe \& Fennema, 1993. The usefulness of it is based on the capacity to maintain the quality, to increase the shelf life, and to contribute to the economic efficiency (Arismendi et al., 2013). New type of packaging materials have been developed and characterized by scientists from natural resources; but despite that, this information is available for the preparation of food wrapping, it is not universal for all products, which poses a challenge for the development of specific coatings and films for each food (Aguirre et al., 2018). The package should satisfy various requirements effectively and economically; for this reason, a new food package should be optimised and integrated effectively with the food supply chain. Changes in the method of distribution chain function, such as the production, distribution, stored and retailed products, reflect the continuing increase for these materials.

Recently, Edible wrapping provide a replacement and/or fortification of the natural layers at the outer surfaces of product to prevent moisture losses, gas aromas and solute movements out of the food, while selectively allowing for controlled exchange of essential gases, such as carbon dioxide, oxygen, and ethylene, which are involved in food product respiration (Embuscado \& Huber, 2009). Furthermore, the materials that are used for this purpose can thoroughly coat the food or can be used as a continuous layer between food components (Guilbert, 1995).

Although edible coatings and films have a similar definition, but there is a difference. Generally, edible films are prepared separately and then applied to the surface of the food, whereas coatings are formed directly onto the food surfaces (Cordeiro, 2012). Although edible films and sheets are not meant to replace traditional packaging entirely, the adequacy of food protection can be improved by combining primary edible packaging and secondary nonedible packaging. Secondary packaging is usually required for handling and hygienic reasons (Cordeiro, 2012). The films or coatings are produced exclusively from renewable, edible elements and therefore are anticipated to degrade more readily than polymeric materials Trinetta. 2016. The coating can enhance the organoleptic properties of packaged foods provided they contain various components (flavourings, colourings, sweeteners) (Bourtoom, 2008). Edible packaging generally consists of edible 
films, sheets, coatings, and pouches. Edible films (thickness $<254 \mu \mathrm{m}$ or $10 \mathrm{mil}$ ) or layers (thickness $>254 \mu \mathrm{m}$ ) are stand-alone structures that are performed separately from the food and then placed on or between food components or sealed into edible pouches, whereas edible films are thin layers (both edible film) of consumable materials formed directly on the surface of the food products (Krochta \& De, 1997; Janjarasskul and Krochta, 2010).

Perishable food products such as fish during postharvest management; there is a considerable loss due to microbes. In the case of vegetables and fruits, there are external factors that include $\mathrm{O}_{2}$ and $\mathrm{CO}_{2}$ content, stress factor, ethylene ratios, and temperature, among others; and internal factors, such as the species, cultivar and its growth stage, that significantly affects the product quality and the risk to the consumers because of the presence of pathogenic microorganism (Bosquez et al., 2003). The fresh products quality factors are essential to ensure marketability. The postharvest losses of fresh products are important issues due to their rapid decay during handling, transportation, and storage (Barbosa et al., 2014; Janjarasskul et al., 2014). The performance of edible packaging depends on the materials used their main characteristics, such as barrier, mechanical, and optical properties. The component of edible packaging material shall be selected according to the type of food (i.e., fruits, soluble coffee, dairy and vegetables) and storage conditions, e.g., temperature and relative humidity (RH) (Parente, 2018).

Materials such as carrageenan and chitosan, polysaccharide-based edible film, have the advantage to be an effective barrier to nonpolar aroma compounds, preventing lipid oxidation and aroma loss (Hambleton et al., 2009). Hydrocolloid-based edible films, such as carboxymethylcellulose and alginate, can be used to retain moisture and decrease fat uptake in deep-fat fried food (Dragich and Krochta, 2009). Edible coating with high water vapour permeability can be used to minimise salt migration into food during brine-freezing processes, while films with selective permeability can help to limit flavour and aroma loss during freeze-drying operations (Janjarasskul and Krochta, 2010). Another factor to be considered, when selecting edible packaging material for food applications, is the ability to be an active carrier for antioxidant and antimicrobial compounds and to be able to manage the migration of molecules from the package to the product. The edible coating has shown excellent delivery properties; therefore, several researchers have explored this promising area for food preservation (Trinetta, 2016).

\section{Classification of edible films and coatings}

The materials used to produce edible packaging, both coatings and films, must meet two requirements; one is to be considered edible, and the other is the ability to form a continuous layer or film. In this group of materials are generally polysaccharides, proteins, and waxes that can create a constant coating or film. They can be divided into different categories according to their production method and origin (Parente, 2018). Edible films and coatings are classified into three main categories based on the materials used for their preparation: Polysaccharides, proteins, lipids (Figure 1). Films are usually prepared by dissolving the edible ingredient in water, alcohol, or a mixture of solvents. Very often, a plasticiser is added to the solution to enhance flexibility and elasticity. Other additives, like antimicrobial agents, colours, and flavour, can be combined with the solution to obtain specific film properties and functionality based on the final application (Janjarasskul and Krochta, 2010). At the 
commercial level, edible films are usually produced by continuous film casting, mold casting, or drawdown bar method (Pascall and Lin, 2013). During casting, the wet film is coated onto a belt conveyor and then passed through a drying chamber, while mold casting and drawdown bar are cheaper and more accessible methods used for lab-scale film production (Trinetta, 2016). Based on sources, edible packaging materials can be grouped like (1) materials from direct biomass or natural sources (e.g., marine, agricultural, and animal sources), typified by proteins, polysaccharides, waxes, and lipids; (2) materials produced by wild or genetically modified microorganisms, such as polysaccharides and some active compounds; (3) materials produced by classical chemical synthesis, including surfactants, plasticizers, and other active compounds that are generally used in edible packaging (Parente, 2018).

\section{Protein-based edible packaging material}

Protein-based edible films can be used for different food products to reduce the loss of moisture, to restrict absorption of oxygen, to reduce migration of lipids, to improve mechanical handling properties, to provide physical protection, or to offer an alternative to synthetic packaging materials. The proteinbased edible coating also offers excellent mechanical and barrier properties against oil, oxygen and aroma. But they are limited resistance to water vapours (Kester \& Fennema, 1986; Raajeswari and Pragatheeswari 2019). Also, protein-based edible films can be applied inside different foods at the interfaces between different layers of components to prevent the deterioration of inter-component.

Moreover, protein-based edible films can be carriers for various additives like antimicrobial and antioxidant agents. They can be used at the food surface to control the diffusion rate of additives substances from the surface to the interior. Together with nonedible films, protein-based edible films have another possible application for their use in multilayer food packaging materials.

Collagen (fibrous proteins) has received the most attention in the production of edible films. Globular proteins of wheat gluten, corn zein, soy protein, whey protein and mung bean protein, have been investigated for their film properties (Wittaya, 2012). Protein-based edible films have the potential to be used for the special packaging of beans, nuts and cashew nuts.

\section{Polysaccharides based edible packaging material}

Polysaccharides are long-chain polymers formed from mono- or disaccharide repeating units joined together by glycosidic bonds. As a result of a large number of hydroxyl groups and other hydrophilic moieties present in their structure, H-bonds play significant roles in film formation and characteristics.

Generally, polysaccharide films are formed by disrupting interactions among long-chain polymer segments during the coacervation process and forming new intermolecular hydrophilic and $\mathrm{H}$-bonding upon evaporation of the solvent to create a film matrix (Janjarasskul and Krochta, 2010).

Polysaccharide coating exhibit excellent aroma, oxygen, and oil barrier properties and they provide strength and structural integrity. However, they also provide very little resistance to water migration. Hydrogenbonded network structure and low solubility provide excellent oxygen barrier properties. The films using polysaccharides may delay in ripening and help in prolonging the shelf life of coated produce (Raajeswari and Pragatheeswari, 2019). 


\section{Lipids based edible packaging material}

Lipid compounds have been utilised as protective wrapping for many years, but since they are not polymers, they do not have a large number of repeating units connected by covalent bonds to form coherent, stand-alone films. Thus, they are fragile and do not generally build cohesive, self-supporting film structures (Greener \& Fennema, 1989). Lipid coating has excellent barrier properties for water vapour and oxygen. Usually, wax films are substantially more resistant to moisture migration than other lipid or non-lipid edible films. Edible resins such as terpene resin, shellac; and wood resin are used to impart gloss to food commodities. Shellac used as an edible wrapping for the confectionary and fresh produce (Raajeswari and Pragatheeswari 2019). Owing to their relatively low polarity, lipids have been incorporated into edible filmforming materials to provide a moisture barrier within composite films (Greener \& Fennema 1989). Nevertheless, there are disadvantages of employing lipids in edible packaging materials, such as their waxy taste and texture, greasy surface, and potential rancidity (Janjarasskul and Krochta, 2010)

\section{Composite Materials}

Composite materials are a combination of edible substance that is made to overcome their flaws (Krochta \& De 1997). Most of the composite films consist of a protein, lipid layer and hydrocolloid components supported by a polysaccharide, or lipid material dispersed in a protein matrix or polysaccharide.

The lipid components used to reduce water transmission while the other components serve as selective gas barriers and provide structural integrity and mechanical strength (Gontard $e t$ al., 1994; Raajeswari and Pragatheeswari 2019).
Edible films based on polar biopolymers, i.e., polysaccharides and proteins, are generally efficient gas barriers and have moderately good mechanical properties at low RH. However, polysaccharides and proteins give water-sensitive films with poor moisturebarrier performance and markedly degraded gas barrier and mechanical properties at high humidity. On the contrary, hydrophobic lipids are effective against moisture migration, but their mechanical properties are much inferior to those of hydrocolloid films because of their nonpolymeric nature.

\section{Use of additives in edible films}

Several materials are incorporated into edible films to enhance structural, mechanical and handling properties or to provide active functions to the coating (Raajeswari and Pragatheeswari 2019). The examples are mentioned below;

\section{Plasticizers}

Plasticizers are typically small-molecularweight hydrophilic agents added to filmforming preparations to improve film mechanical properties by situating themselves in their polymeric network and competing for chain-to-chain $\mathrm{H}$-bonding along the polymer chains (Janjarasskul and Krochta, 2010). Plasticisers are generally added to edible films for enhancement in flexibility and durability. These include mono-, di-, or oligosaccharides like glucose, fructose-glucose syrups and sucrose, polyols like glycerol, glyceryl derivatives, sorbitol and polyethylene glycols; lipids; and derivatives like phospholipids, fatty acids and surfactants (Raajeswari and Pragatheeswari, 2019).

\section{Emulsifiers}

Emulsifiers are surface-active compounds, with both polar and nonpolar character, 
capable of modifying interfacial energy at the interface of immiscible systems, such as a water-lipid interface or a water-air surface (Janjarasskul and Krochta, 2010). Emulsifiers are essential to attain sufficient surface wetability to ensure proper surface coverage and adhesion to the wrapped surface as well as for the formation and stabilisation of welldispersed lipid (Raajeswari and Pragatheeswari, 2019).

\section{Antimicrobials}

One of the significant emerging functions of edible coatings is their use as carriers of antifungal and antimicrobials agents to enhance the shelf life of foods products; they also used as carriers of nutrients to increase the nutritional value of final processed food products. Incorporation of both natural and synthetic antimicrobial agents into various edible packaging has been developed as a useful alternative for controlling the growth of microorganisms (Janjarasskul and Krochta, 2010). The most commonly used antimicrobials are organic acids; nisin; chitosan; lactoperoxidase system; and some plant extracts and their essential oils (Raajeswari and Pragatheeswari, 2019)

\section{Antioxidants}

Antioxidants are added to edible packaging materials to delay the rate of oxidation reactions. The examples of antioxidants include butylatedhydroxytoluene (BHT), butylatedhydroxyanisole (BHA), propyl gallate, tertiary butylhydroquinone, ascorbic acid, citric acid, ascorbyl palmitate and tartaric acid (Raajeswari and Pragatheeswari. 2019).

\section{Organic acids and their salts}

Benzoic acid and its salts are most effective in the undissociated form at $\mathrm{pH} 2.5-4.0$. This preservative is more active against yeasts and molds than bacteria. Sorbic acid and its salts are useful in $\mathrm{pH}$ range 3.0-6.5 against a broad spectrum of yeast and molds and lactic acid bacteria. Acetic, lactic, propionic, and fumaric acids also can be used in coatings and contribute to antimicrobial activity (Janjarasskul and Krochta, 2010).

\section{Chitosan}

Chitosan's antimicrobial activity is most effective against yeasts and molds, followed by gram-positive bacteria and gram-negative bacteria.

Its mechanism of antimicrobial action was proposed to be a harmful leakage of microbial proteinaceous and intercellular components as a result of the interaction between positively charged chitosan and the negatively charged microbial cell membrane. Chitosan also chelates trace metals, thus preventing microbial growth and toxin production (Cuero et al., 1991).

\section{Plant extracts}

Essential oil extracts from plants, e.g., grapefruit seed, cinnamon, allspice, clove, thyme, rosemary, onion, garlic, radish, mustard, horseradish, and oregano, are rich in phenolic compounds such as flavonoids and phenolic acids, which exhibit a broad range of biological effects, including antioxidant and antimicrobial activity (Oussalah et al., 2004). These naturally occurring antimicrobial agents can be added into foods without labelling as antimicrobial agents or preservatives (Suppakul et al., 2003).

\section{Bacteriocins}

Bacteriocins are protein-containing macromolecules produced by various bacteria and possessing different antibacterial spectra, modes of action, and chemical properties. 
Fig.1 Classification of edible food packaging material

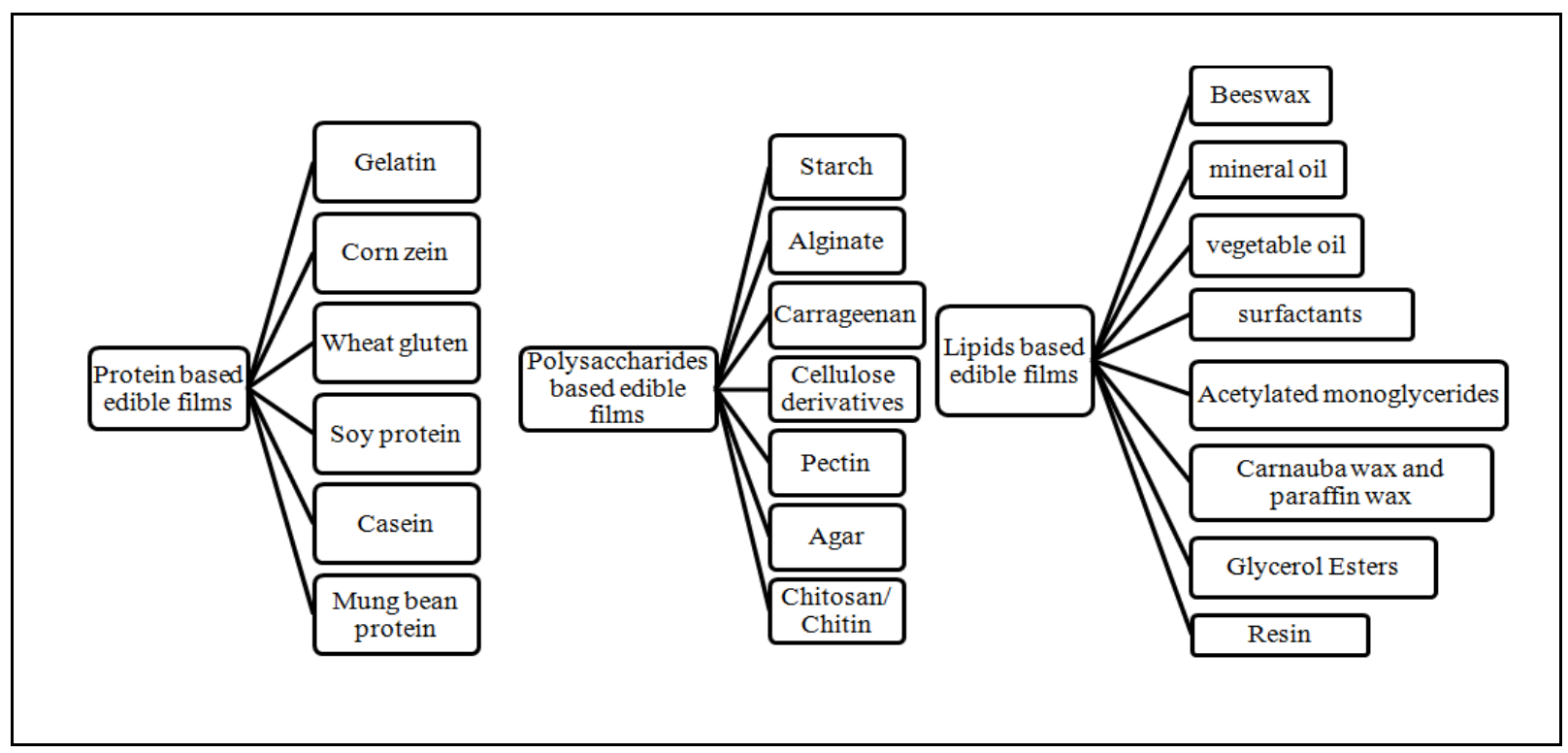

They are generally heat stable, hypoallergenic, and readily degraded by proteolytic enzymes in the human intestinal tract. Numerous bacteriocins have been characterised, such as colicins (Escherichia coli), lacticin (Lactococcus lactis), pediocins (Pediococcus acidilactici), and nisin (Lactococcus lactis). Nisin remained the most commercially important bacteriocin because of its history of safe use and documented effectiveness against gram-positive pathogenic and spoilage bacteria. Nisin interacts with the sulfur-containing compounds in bacterial membranes, disrupting their semipermeable function and causing cell lysis (Thomas et al., 2000).

\section{Enzyme}

Lysozyme and lactoperoxidase are widely studied antimicrobial enzymes isolated from various natural sources, e.g., milk. Lysozyme is a single-chain protein that possesses the ability to hydrolyze $\beta \quad(1 \rightarrow 4)$ glycosidic linkages between $\mathrm{N}$-acetylmuramic acid and $\mathrm{N}$-acetylglucosamine found in peptidoglycan cell walls of both gram-positive and gramnegative bacteria. The loss of structural integrity of the cell walls causes lysis of bacterial cells (Shah 2000). Lysozyme is less effective against gram-negative bacteria, because of the lipid-based outer membrane over their cell walls.

\section{Role and function of edible packaging}

\section{Edibility and biodegradability}

To maintain their edibility and biodegradability, all film components should be made from food-grade ingredients and biodegradable (environmentally safe).

\section{Physical and mechanical protection}

The packaging of food can retard product deterioration, retain the beneficial effects of processing, enhance shelf-life, and maintain the quality and safety of food. In doing so, it protects three significant classes of external influences: physical, chemical and biological. Chemical protection reduces compositional changes triggered by environmental impacts such as exposure to gases (typically oxygen, carbon oxide), moisture (gain or loss), or light (visible, infrared, or ultraviolet). Biological 
protection provides a barrier to microorganisms (spoilage and pathogenic agents), rodents, insects, and other animals, thereby preventing disease and deterioration. Also, biological barriers maintain conditions to control senescence (ripening and ageing). Such restrictions function via a multiplicity of mechanisms, including preventing odour transmission, preventing access to the product, and maintaining the environment inside the package. Physical protection shields food from mechanical damage and includes cushioning against the shock and vibration encountered during transportation. Typically developed from paperboard and corrugated materials, physical barriers resist impacts, crushing and abrasions damage, so they are used as shipping containers and as packaging for delicate foods such as fresh fruits and eggs. Appropriate physical packaging materials also protect consumers from various health hazards. Also, the substitution of plastic packaging for products ranging from shampoo to soda bottles has reduced the danger from broken glass containers (Kenneth and Betty, 2007). Mechanical properties should be optimised regarding elastic modulus, tensile strength, elongation-at-break, compression strength, stiffness, puncture strength, tearing strength, burst strength, folding endurance, abrasion resistance, adhesion force, etc. (Han, 2014; Suput et al., 2015)

\section{Migration, permeation, and barrier functions}

All barrier properties are affected by the material composition and environmental conditions (temperature and relative humidity).

\section{Convenience and quality preservation}

Edible film and coating can retard surface dehydration, moisture absorption, oxidation of ingredients, frying oil absorption, aroma loss, ripening/ageing, and microbial spoilage of food products. They also contribute to visual quality, flavour carriage, surface smoothness, edible colour printing, and other marketing-related quality factors.

\section{Shelf-life extension and safety enhancement}

An increased protective function of food a product enhances shelf life and reduces the possibility of contamination by foreign matter.

\section{Active substance carriers and controlled release}

Edible films and can be utilised for food ingredients, agrochemicals pharmaceuticals and nutraceuticals. In the form of soluble strips, flexible pouches capsules, microcapsules, and covering on hard particles. Biodegradable films can be produced by using two basic techniques.

The first technique uses wet solvent processing, commonly known as solution casting. Solution casting was developed over one hundred years ago. Using this method, solutions are spread onto levelled plates like acrylic, silicon or Teflon plates, followed by a drying process at ambient conditions or under controlled conditions, controlled relative humidity, hot air, infrared energy, microwave energy (Dangaran and Tomasula, 2009).

After the 1950s, the use of extrusion was employed for the manufacture of thermoplastic polymers and extrusion became the dominant production method used for plastics manufacture. Extrusion uses elevated temperature and shear to soften and melt the polymer (resins), thereby allowing a cohesive film matrix to form (Dangaran and Tomasula, 2009). 
The concept of edible packaging material represents a stimulating route for creating new packaging materials. This is because they are available with a wide range of properties that can help to alleviate many problems encountered with foods. Edible films and coatings can be produced from materials with film-forming ability. However, potential applications and functions of the films and coatings warrant increased considerations. The selected coating formulations reduce gas transfer rates and can be, therefore, essential tools to extend the shelf life of foods. A good choice of the coating formulation is necessary for the durability and maintenance of the coating on the food products. Despite the advantages of edible materials which have been presented by scientists, several obstacles in their development potential have to be overcome, such as cost-effectiveness, technological application and improved water vapour permeability barrier methods.

\section{References}

Aguirre-Joya, J.A., De Leon-Zapata, M.A., Alvarez-Perez, O.B., Torres-León, C., Nieto-Oropeza, D.E., VenturaSobrevilla, J.M., Aguilar, M.A., RuelasChacón, X., Rojas, R., RamosAguiñaga, M.E. and Aguilar, C.N., 2018. Basic and applied concepts of edible packaging for foods. In Food packaging and preservation, Academic Press, pp. 1-61.

Ahmad, V., Khan, M.S., Jamal, Q.M.S., Alzohairy, M.A., Al Karaawi, M.A. and Siddiqui, M.U., 2017. Antimicrobial potential of bacteriocins: in therapy, agriculture and food preservation. Int. J. Antimicrob. Agents., 49, 1-11.

Ahvenainen, R., 2003. Active and intelligent packaging: an introduction. In Novel food packaging techniques. pp. 5-21.

Ali, A., Maqbool, M., Ramachandran, S. and Alderson, P.G., 2010. Gum arabic as a novel edible coating for enhancing shelf-life and improving postharvest quality of tomato (Solanum lycopersicum L.) fruit. Postharvest Biol. Technol., 58, 42-47.

Arismendi, C., Chillo, S., Conte, A., Del Nobile, M.A., Flores, S. and Gerschenson, L.N., 2013. Optimization of physical properties of xanthan gum/tapioca starch edible matrices containing potassium sorbate and evaluation of its antimicrobial effectiveness. LWT- Food Sci. Technol., 53, 290-296.

Barbosa-Pereira, L., Angulo, I., Lagarón, J.M., Paseiro-Losada, P. and Cruz, J.M., 2014. Development of new active packaging films containing bioactive nanocomposites. Innov. Food Sci. Emerg. Technol., 26, 310-318.

Bosquez-Molina, E., Guerrero-Legarreta, I. and Vernon-Carter, E.J., 2003. Moisture barrier properties and morphology of mesquite gum-candelilla wax based edible emulsion coatings. Food Res. Int., 36, 885-893.

Bourtoom, T., 2008. Edible films and coatings: characteristics and properties. Int. Food Res. J., 15, 237-248.

Coles, R., McDowell, D. and Kirwan, M.J. eds., 2003. Food packaging technology (Vol. 5). CRC Press.

Cuero, R.G., Osuji, G. and Washington, A., 1991. N-carboxymethylchitosan inhibition of aflatoxin production: role of zinc. Biotechnol. Lett., 13, 441-444.

Dangaran, K., Tomasula, P.M. and Qi, P., 2009. Structure and function of proteinbased edible films and coatings. In Edible films and coatings for food applications. Springer, New York, NY, pp. 25-56.

Donhowe, I.G. and Fennema, O., 1993. The effects of plasticizers on crystallinity, permeability, and mechanical properties of methylcellulose films. J. Food 
Process. Preserv., 17, 247-257.

Dragich, A.M. and Krochta, J.M., 2010. Whey protein solution coating for fat- uptake reduction in deep- fried chicken breast strips. J. Food Sci., 75, S43-S47.

Embuscado, M.E. and Huber, K.C., 2009. Edible films and coatings for food applications (Vol. 9). New York: Springer.

FAO, 2011. Global Food, and Food Waste. "Extent, causes and prevention." Rome: Food and Agriculture Organization of the United Nations.

Gómez-Estaca, J., López-de-Dicastillo, C., Hernández-Muñoz, P., Catalá, R. and Gavara, R., 2014. Advances in antioxidant active food packaging. Trends Food Sci. Technol., 35, 42-51.

Gontard, N., Duchez, C., CUQ, J.L. and Guilbert, S., 1994. Edible composite films of wheat gluten and lipids: water vapour permeability and other physical properties. International journal of food science \& technology, 29, 39-50.

Greener, I.K. and Fennema, O., 1989. Barrier properties and surface characteristics of edible, bilayer films. J. Food Sci., 54, 1393-1399.

Guilbert, S., Gontard, N. and Cuq, B., 1995. Technology and applications of edible protective films. Packaging Technology and Science, 8, 339-346.

Hadian, M., Rajaei, A., Mohsenifar, A. and Tabatabaei, M., 2017. Encapsulation of Rosmarinus officinalis essential oils in chitosan-benzoic acid nanogel with enhanced antibacterial activity in beef cutlet against Salmonella typhimurium during refrigerated storage. LWT, 84, 394-401.

Hambleton, A., Debeaufort, F., Bonnotte, A. and Voilley, A., 2009. Influence of alginate emulsion-based films structure on its barrier properties and on the protection of microencapsulated aroma compound. Food Hydrocoll., 23, 21162124.

Han, J.H., 2014. Innovations in food packaging, Elsevier, Academic Press, USA.

Hannon, J.C., Kerry, J.P., Cruz-Romero, M., Azlin-Hasim, S., Morris, M. and Cummins, E., 2017. Kinetic desorption models for the release of nanosilver from an experimental nanosilver coating on polystyrene food packaging. Innov. Food Sci. Emerg. Technol., 44, 149158.

Janjarasskul, T. and Krochta, J.M., 2010. Edible packaging materials. Annu. Rev. Food Sci. Technol., 1, 415-448.

Janjarasskul, T., Rauch, D.J., McCarthy, K.L. and Krochta, J.M., 2014. Barrier and tensile properties of whey proteincandelilla wax film/sheet. LWT- Food Sci. Technol., 56, 377-382.

Kester, J.J. and Fennema, O.R., 1986. Edible films and coatings: a review. Food Technol. (USA).

Krochta JM, De Mulder-Johnston C., 1997. Edible and biodegradable polymer films: challenges and opportunities. Food Technol., 51, 61-73

Lin, L., Abdel-Shafi Abdel-Samie, M., \& Cui, H., 2018. Novel Packaging Systems in Food. Reference Module in Food Science. 484-491.

MacGowan, A., Macnaughton, E., 2017. Antibiotic resistance. Med. Baltim. 45, 622-628.

Marsh, K. and Bugusu, B., 2007. Food packaging-roles, materials, and environmental issues. J. Food Sci., 72, 39-55.

Nordström, R. and Malmsten, M., 2017. Delivery systems for antimicrobial peptides. Adv. Colloid Interface Sci., 242, 17-34.

Oussalah, M., Caillet, S., Salmiéri, S., Saucier, L. and Lacroix, M., 2004. Antimicrobial and antioxidant effects of 
milk protein-based film containing essential oils for the preservation of whole beef muscle. J. Agr. Food Chem., 52, 5598-5605.

Parente Ribeiro Cerqueira, M. Â., 2018. Edible Packaging. Reference Module in Food Science. 173-176.

Pascall, M.A. and Lin, S.J., 2013. The application of edible polymeric films and coatings in the food industry. $J$. Food Process. Technol.

Raajeswari P.A., and Pragatheeswari R., 2019. Edible Packaging and Market Overview., Food Marketing \& Technology, Indian addition, article.

Ribeiro-Santos, R., Andrade, M. and SanchesSilva, A., 2017. Application of encapsulated essential oils as antimicrobial agents in food packaging. Curr. Opin. Food Sci., 14, 78-84.

Rodrigues, S. and Fernandes, F.A.N., 2012. Advances in fruit processing technologies. CRC Press.

Shah, N.P., 2000. Effects of milk-derived bioactives: an overview. Br. J. Nutr.,
84, 3-10.

Suppakul, P., Miltz, J., Sonneveld, K. and Bigger, S.W., 2003. Active packaging technologies with an emphasis on antimicrobial packaging and its applications. J. Food Sci., 68, 408-420.

Suput, D.Z., Lazić, V.L., Popović, S.Z. and Hromiš, N.M., 2015. Edible films and coatings: Sources, properties and application. Food and Feed Research, 42, 11-22.

Thomas, L.V. and Delves-Broughton, J., 2005. 7 Nisin. Antimicrobials in food, 237.

Tian, F., Decker, E.A. and Goddard, J.M., 2013. Controlling lipid oxidation of food by active packaging technologies. Food Funct., 4, 669-680.

Trinetta, V., 2016, "Biodegradable Packaging." Reference Module in Food Science, 2-4.

Wittaya, T., 2012. Protein-based edible films: Characteristics and improvement of properties. Structure and function of food engineering, 43-70.

\section{How to cite this article:}

Pooja Saklani, Siddhnath, Sambit Kishor Das and Shiv Mohan Singh. 2019. A Review of Edible Packaging for Foods. Int.J.Curr.Microbiol.App.Sci. 8(07): 2885-2895. doi: https://doi.org/10.20546/ijcmas.2019.807.359 